\title{
Isolation and Antimicrobial Testing of Aeromonas spp., Citrobacter spp., Cronobacter spp., Enterobacter spp., Escherichia spp., Klebsiella spp., and Trabulsiella spp. from the Gallbladder of Pigs
}

\author{
GRAMMATO EVANGELOPOULOU ${ }^{1 *}$, GEORGIOS FILIOUSSIS², SPYRIDON KRITAS², \\ MARIA KANTERE ${ }^{1}$ and ANGELIKI R. BURRIEL ${ }^{1}$ \\ ${ }^{1}$ Laboratory of Microbiology and Parasitology, Faculty of Veterinary Medicine, School of Health Sciences, \\ University of Thessaly, Karditsa, Greece \\ ${ }^{2}$ Department of Microbiology and Infectious Diseases, Faculty of Veterinary Medicine, \\ Aristotle University, Thessaloniki, Greece
}

Submitted 2 December 2014, revised 1 March 2015, accepted 17 March 2015

\begin{abstract}
The presence of Gram-negative bacteria species, other than Salmonella spp., in the gallbladder of pigs was examined. Isolated Gram-negative bacteria were assigned to species using the Microgen ${ }^{\mathrm{TM}} \mathrm{GnA}+\mathrm{B}-\mathrm{ID}$ Systems. Of the 64 isolated strains 43 were identified as Escherichia coli, seven as Enterobacter spp., three each as Klebsiella spp., Citrobacter freundii, Aeromonas hydrophila and Cronobacter sakazakii and one each as Escherichia fergusonii and Trabulsiella guamensis. Their antibiograms showed very high resistance to ampicillin, amoxicillin, tetracycline, chloramphenicol and sulfamethoxazole/trimethoprim. It was concluded that the pigs' gallbladder is a reservoir of potentially pathogenic Gram-negative bacteria for pork consumers.
\end{abstract}

Ke y w ords: aztreonam, cholecystitis, doripenem, microflora of gallbladder, potentially pathogenic Gram-negative bacteria

Enteric bacteria have acquired the genetic ability to resist the defence mechanisms of the digestive system, some of which are gastric secretions, hydrochloric acid and bile, variations in $\mathrm{pH}$, low oxygen levels, nutrient limitations and elevated osmolarity (Chowdhury et al., 1996). By this ability, they are either pathogenic or potentially pathogenic for their host. If such bacteria colonize the gallbladder of pigs, they could become pork contaminants and a risk to consumers (Gunn, 2000). Bile is for some bacteria the regulating factor of their survival in the intestinal tract, thus a regulator of gut colonization. They survive the killing effect of bile, but also antibiotics and the host's immune response by forming protective biofilms (Begley et al., 2005; Jensen et al., 2010). Hence, the microflora of the gallbladder is evidence of an animal's intermittent gut colonization by potential pathogens.

Therefore, the objective was to asses Gram-negative bacteria of the pig's gallbladder, as risks to pork consumers.

Swab samples collected at slaughter from 145 randomly selected pigs' gallbladders, originating from
15 finishing farms located in Central Greece were bacteriologically examined.

Samples were enriched in Buffered Peptone Water (BPW Oxoid, England) for $18 \pm 2 \mathrm{~h}$ at $37^{\circ} \mathrm{C}$ and subcultured on Columbia Blood Agar (CBA) and MacConkey agar (Oxoid, England). All morphologically different colonies were subcultured on CBA and after $24 \mathrm{~h}$ at $37^{\circ} \mathrm{C}$, they were examined by Gram's stain. Gram-negative rods were tested for oxidase production (Bactident Oxidase Merck, Germany) and further examined as recommended by Quinn et al. (1994). In total, 79 Gram-negative isolates were selected for speciation using the Microgen ${ }^{\mathrm{TM}} \mathrm{Gn} A+\mathrm{B}-\mathrm{ID}$ (Microgen Bioproducts Ltd, UK) System.

Sixty four non Salmonella species were tested against 24 antimicrobial agents using the disk diffusion method, as described elsewhere (Evangelopoulou et al., 2014a). The selection of the antimicrobials was based on their use for treating animal and human infections. They were amoxicillin $(30 \mu \mathrm{g})$, amoxicillin/clavulanic acid $(20 / 10 \mu \mathrm{g})$, ampicillin $(10 \mu \mathrm{g})$, ampicillin/sulbac$\operatorname{tam}(10 / 10 \mu \mathrm{g})$, aztreonam $(30 \mu \mathrm{g})$, cefotaxime $(30 \mu \mathrm{g})$,

* Corresponding author: G. Evangelopoulou, Laboratory of Microbiology and Parasitology, Faculty of Veterinary Medicine, School of Health Sciences, University of Thessaly, Karditsa, Greece; e-mail: matinavet@hotmail.com 
cefoxitin $(30 \mu \mathrm{g})$, ceftazidime $(30 \mu \mathrm{g})$, ceftiofur $(30 \mu \mathrm{g})$, ceftriaxone $(30 \mu \mathrm{g})$, cefuroxime $(30 \mu \mathrm{g})$, chloramphenicol $(30 \mu \mathrm{g})$, colistin $(50 \mu \mathrm{g})$, doripenem $(10 \mu \mathrm{g})$, enrofloxacin $(5 \mu \mathrm{g})$, erythromycin $(15 \mu \mathrm{g})$, gentamicin $(10 \mu \mathrm{g})$, kanamycin $(30 \mu \mathrm{g})$, nalidixic acid $(30 \mu \mathrm{g})$, penicillin G $(10 \mu \mathrm{g})$, rifampin $(30 \mu \mathrm{g})$, sulfamethoxazole/ trimethoprim $(23.75 / 1.25 \mu \mathrm{g})$, tetracycline $(30 \mu \mathrm{g})$ and tigecycline $(15 \mu \mathrm{g})$. Isolates exhibiting resistance to at least three antimicrobial agents belonging to different antimicrobial classes were considered multidrug resistant (MDR) (Schwarz et al., 2010).

Of the 93 (64.1\%) bacteria positive gallbladders, 79 Gram-negative bacteria were selected for speciation. Of them 15 were identified as Salmonella spp. and 64 were Escherichia coli (43), Enterobacter spp. (7), three each Klebsiella spp., Citrobacter freundii, Aeromonas hydrophila and Cronobacter sakazakii and one each E. fergusonii and T. guamensis (Table I). The three A. hydrophila isolates exhibited beta-haemolysis after 48 hours of incubation.

High antimicrobial resistance was observed for ampicillin, amoxicillin, tetracycline, chloramphenicol and sulfamethoxazole/trimethoprim (Table I). Somewhat lower was resistance to cephalosporins, quinolones and aminoglycosides, as groups. All isolates, except one (E. fergusonii), were resistant to penicillin $\mathrm{G}$ and all were susceptible to aztreonam and doripenem used for human treatments. Sixty isolates were considered MDR (Table I).

Of the 79 Gram-negative 15 were Salmonella spp. published elsewhere (Evangelopoulou et al., 2014b). Of the remaining, E. coli forming the normal intestinal microbiota was the predominant aerobic microorganism identified by the Microgen System. E. coli is helpful

Table I

Cumulative results of antimicrobial resistance of Gram-negative isolates recovered from pigs' gallbladder

\begin{tabular}{|c|c|c|c|c|c|c|c|c|c|c|c|}
\hline & 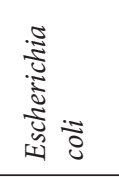 & 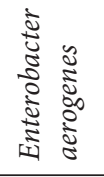 & 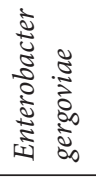 & 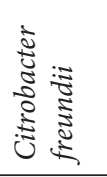 & 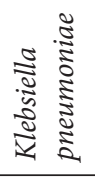 & 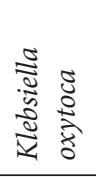 & 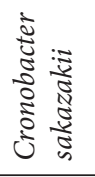 & 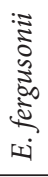 & 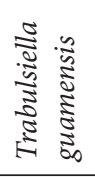 & 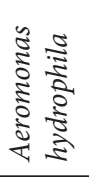 & 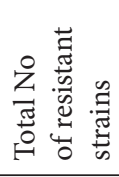 \\
\hline AML & 37 & 3 & 3 & 2 & 1 & 1 & 1 & 0 & 1 & 3 & 52 \\
\hline AMC & 12(I) & 3 & 0 & $1,1(\mathrm{I})$ & 0 & 1 & 0 & 0 & 1 & 3 & 9 \\
\hline AMP & 37 & 3 & 3 & 2 & 1 & 1 & 2 & 0 & 1 & 3 & 53 \\
\hline SAM & $4,8(\mathrm{I})$ & $1(\mathrm{I})$ & 0 & 1 & 0 & 1 & 1 & 0 & 0 & 1 & 8 \\
\hline AZT & 0 & 0 & 0 & 0 & 0 & 0 & 0 & 0 & 0 & 0 & 0 \\
\hline CTX & 2(I) & 0 & 0 & 0 & 0 & 0 & 0 & 0 & 0 & 3 & 3 \\
\hline FOX & $1(\mathrm{I})$ & 0 & $1(\mathrm{I})$ & 2(I) & 0 & 1 & $1(\mathrm{I})$ & 0 & 1 & 3 & 5 \\
\hline CAZ & 1(I) & 0 & 0 & 1 & 0 & 0 & 0 & 0 & 0 & 0 & 1 \\
\hline EFT & 1(I) & 0 & 0 & 1(I) & 0 & 0 & 0 & 0 & 0 & 3 & 3 \\
\hline $\mathrm{CRO}$ & 1 & 0 & 0 & 1 & 0 & 0 & 0 & 0 & 0 & 3 & 5 \\
\hline CXM & $1,13(\mathrm{I})$ & $3(\mathrm{I})$ & $1(\mathrm{I})$ & 3(I) & 0 & 1(I) & 2(I) & 0 & 0 & 3 & 4 \\
\hline $\mathrm{CT}$ & 0 & 0 & 0 & 1 & 0 & 1 & 0 & 0 & 0 & 0 & 2 \\
\hline $\mathrm{C}$ & 31 & 2 & 0 & 2 & 0 & 2 & 0 & 0 & 0 & 3 & 40 \\
\hline DOR & 0 & 0 & 0 & 0 & 0 & 0 & 0 & 0 & 0 & 0 & 0 \\
\hline ENR & $2,2(\mathrm{I})$ & 0 & 0 & 1(I) & 0 & 0 & 0 & 0 & 0 & $1(\mathrm{I})$ & 2 \\
\hline $\mathrm{E}$ & 39 & 3 & 4 & 3 & 1 & 2 & 3 & 1 & 1 & 3 & 60 \\
\hline $\mathrm{CN}$ & $2,1(\mathrm{I})$ & 0 & 0 & 1 & 0 & 0 & 0 & 0 & 0 & 0 & 3 \\
\hline K & $4,7(\mathrm{I})$ & 0 & 1(I) & 1 & 0 & 1 & 0 & 0 & 0 & 2 & 8 \\
\hline NA & $5,4(\mathrm{I})$ & 0 & 0 & 1 & 0 & 1 & 0 & 0 & 0 & 3 & 10 \\
\hline $\mathrm{P}$ & 43 & 3 & 4 & 3 & 1 & 2 & 3 & 0 & 1 & 3 & 63 \\
\hline $\mathrm{RD}$ & $21,19(\mathrm{I})$ & $2,1(\mathrm{I})$ & 4 & 3 & 1 & 2 & $2,1(\mathrm{I})$ & 0 & 1 & 3 & 39 \\
\hline SXT & 39 & 2 & 0 & 2 & 0 & 2 & 1 & 0 & 1 & 3 & 50 \\
\hline $\mathrm{TE}$ & 39 & 2 & 0 & 2 & 1 & 2 & 2 & 0 & 1 & 3 & 52 \\
\hline TGC & 9(I) & $2(\mathrm{I})$ & $1(\mathrm{I})$ & 0 & $1(\mathrm{I})$ & $1(\mathrm{I})$ & 0 & 0 & 0 & 3 & 3 \\
\hline Total N. & 43 & 3 & 4 & 3 & 1 & 2 & 3 & 1 & 1 & 3 & 64 \\
\hline
\end{tabular}

AML Amoxicillin, AMC Amoxicillin-clavulanic acid, AMP Ampicillin, SAM Ampicillin-sulbactam, AZT Aztreonam, CTX Cefotaxime, FOX Cefoxitin, CAZ Ceftazidime, EFT Ceftiofur, CRO Ceftriaxone, CXM Cefuroxime, C Chloramphenicol, CT Colistin, ENR Enrofloxacin, E Erythromycin, CN Gentamycin, $K$ Kanamycin, NA Nalidixic acid, $P$ Penicillin G, RD Rifampin, SXT Sulfamethoxazole/Trimethoprim, TE Tetracycline, TGC Tigecycline$(\mathrm{I})=$ Intermediate Resistance 
in the development of a normal mucosal immune system, the suppression of harmful bacteria by overtaking their attachment sites and the production of essential nutrients (Canny and McCormick, 2008). However, pathogenic strains could invade the gallbladder and lead to its inflammation (Gunn, 2000). These strains and Klebsiella pneumoniae, Enterobacter spp. and Enterococcus spp. are associated with infectious cholecystitis (Wang et al., 2003; Abeysuriya et al., 2008; Carpender and Gilpin, 2014). Thus, enteric bacteria have developed sophisticated mechanisms not only for resisting the effects of bile salts, but also using favorably this unique environment for their survival, thus becoming under certain circumstances potential pathogens.

Among them could also be T. guamensis and C. freundii. The two could be confused, due to their phenotypic and antigenic behaviour, with Salmonella spp. or E. coli (McWhorter et al., 1991; Delgado et al., 2013), if a variety of methods for their differentiation are not used. Specifically, T. guamensis does not rapidly ferment lactose or sucrose and produces abundantly $\mathrm{H}_{2} \mathrm{~S}$, resembling phenotypically Salmonella enterica subspecies diarizonae and subspecies hountanae (McWhorter et al., 1991). Although its clinical significance for animals is unknown, it could cause diarrhoea, as it does in man, resembling mild salmonellosis. Furthermore, carrier animals could be the source for these occasional human enteric problems.

C. freundii, a commensal microorganism of undocumented clinical importance to animals, is isolated from serious nosocomial infections in man (Nayar et al., 2014). Its pathogenicity is attributed to multidrug resistance (Pepperell et al., 2002), a property observed also in the present investigation (Table I). Evolutionary acquisition of resistance genes affects the course of an infectious disease, the evasion of the immune response and the events of host-pathogen interactions (Delgado et al., 2013).

The same events could be important in human infections caused by multiresistant Enterobacter spp., as observed here, a bacterium easily acquiring resistance genes, mainly to beta-lactams, quinolones, tetracycline and chloramphenicol, thus emerging as a public health risk (Thiolas et al., 2005; Boban et al., 2011). The two species isolated here, Enterobacter aerogenes and Enterobacter gergoviae, are associated to infections of immunocompromised individuals (Boban et al., 2011), as is also Klebsiella spp. showing phenotypic and DNA relatedness to E. aerogenes (Brisse et al., 2006). K. pneumoniae, causing sporadic disease in individual pigs (AHVLA, 2012), is implicated in human pneumonia, urinary tract infections, neonatal septicemia and liver abscesses (Chang et al., 2000; Bleich et al., 2008).

C. sakazakii, previously a species of the genus Enterobacter, is reclassified as a new genus within the family of Enterobacteriaceae (Iversen et al., 2007). Although its pathogenic importance is unknown in animals and adult man, it has been recently implicated in fetal fatal meningitis, neurologic damage, brain abscess, septicemia, etc. (Healy et al., 2010; Joseph and Forsythe, 2011). This association raises questions as to its role with immunocompromised pork consumers.

A. hydrophila, incriminated in a variety of human clinical conditions, such as gastroenteritis, septicemia, cellulitis, myonecrosis, peritonitis, hepatitis, pancreatic abscesses, respiratory, urogenital and eye infections of immunocompromised individuals, is also implicated in infections of poikilothermic animals (amphibians, reptiles and fish) (Janda and Abbott, 2010). However, it is more often isolated from food of plant and animal origin than animal disease (Queiroga et al., 2012). A. hydrophila is producing haemolysins, enterotoxin (Ljungh et al., 1981) and is multidrug resistant (Queiroga et al., 2012), as it was observed here. Its isolation from pig gallbladders and its resistance to most of the antibiotics tested here, support its classification as an emerging pathogen for animals and man. Although the above microbes are opportunistic pathogens, their high resistance to commonly used antimicrobials makes them potential pathogens for man, and perhaps, unrecognized causes of reduced animal productivity.

Additionally, the multidrug resistance observed here indicates that pigs are a primary reservoir of multi-resistant bacteria. The use of antimicrobials in food producing helps faecal excretion of highly pathogenic Gram-negative enteric bacteria, such as Salmonella, eventually making pork carcasses the source of pork product contamination, thus consumer infections (Friendship et al., 2009).

Observed high resistance above $60 \%$ to chloramphenicol, used in the treatment of human salmonellosis, but no longer used in animals in the EU (EVMP, 1994) could result from a variety of reasons. Although non-compliance of farmers is one reason, the number of farms participating (15 farms) is not supportive. Thus it could result from transfer of resistance genes between different bacteria species coding for similar classes of antimicrobials and/be residual caused by the persistence of resistance genes encoded in a microbial resistome (Sommer and Dantas, 2011). Persistent antimicrobial resistance is transferrable not only to pathogens, but also commensal bacteria or opportunistic pathogens, like the above, helping the development of a "superbug" (Thiolas et al., 2005; Shailesh et al., 2012; Frye and Jackson, 2013).

Such events in natural bacteria populations may have important implications in the evolution of bacteria and the means of evading the immune system, thus the outcome of infectious diseases (Delgado, et al., 2013). Hence, pathogenic microorganisms can reside 
transiently or permanently in the gallbladder of pigs, making it a reservoir of multidrug resistant Gram-negative bacteria contaminating pork products and infecting consumers.

\section{Literature}

Abeysuriya V., K.I. Deen, T. Wijesuriya and S.S. Salgado. 2008. Microbiology of gallbladder bile in uncomplicated symptomatic cholelithiasis. Hepatobiliary Pancreat. Dis. Int. 7: 633-637. Animal Health and Veterinary Laboratory Agencies (AHVLA). 2012. KLEBSIELLA SEPTICAEMIA. Information for farmers and vets in Great Britain Animal Health and Veterinary Laboratory. http://www.defra.gov.uk/ahvla-en/files/pub-vet-klebsiella.pdf, 2014.11.17

Begley M., C.G.M. Gahan and C. Hill. 2005. The interaction between bacteria and bile. FEMS Microbiol. Rev. 29: 625-651.

Bleich A., P. Kirsch, H. Sahly, J. Fahey, A. Smoczek, H.J. Hedrich and J.P. Sundberg. 2008. Klebsiella oxytoca: opportunistic infections in laboratory rodents. Lab. Anim. 42: 369-375.

Boban N., A. Jeronic and V. Punda-Polic. 2011. Outbreak of nosocomial bacteremias, caused by Enterobacter gergoviae and Enterobacter aerogenes, in the neonatal intensive care unit, case-control study. SIGNA VITAE. 6: 27-32.

Brisse S., Grimont F. and P.A.D. Grimont. 2006. The Genus Klebsiella, pp. 159-196. In: Dworkin M., S. Falkow, E. Rosenberg, K.H. Schleifer and E. Stackebrandt (eds). Prokaryotes, $3^{\text {rd }}$ ed. Vol. 6. Springer, New York.

Canny G.O. and B.A. McCormick. 2008. Bacteria in the Intestine, Helpful Residents or Enemies from Within? Infect. Immun. 76: 3360-3373.

Carpender C.F. and N. Gilpin. 2014. Cholecystitis. Johns Hoplins Medicine. http://www.hopkinsguides.com/hopkins/ub/view/ Johns_Hopkins_ABX_Guide/540122/all/Cholecystitis, 2014.11.17. Chang S.C., C.T. Fang, P.R. Hsueh, Y.C. Chen and K.T. Luh. 2000. Klebsiella pneumoniae isolates causing liver abscess in Taiwan. Diagn. Microbiol. Infect. Dis. 37: 279-284.

Chowdhury R., G.K. Sahu and J. Das. 1996. Stress response in pathogenic bacteria. J. Biosci. 21: 149-160.

Delgado G., V. Souza, R. Morales, R. Cerritos, A. Gonza'lez-Gonza'lez, J.L. Mendez, V. Vázquez and A. Cravioto. 2013. Genetic characterization of atypical Citrobacter freundii. PLoS ONE 8(9): e74120.

Evangelopoulou G., S. Kritas, A. Govaris and A.R. Burriel. 2014a. Pork meat as a potential source of Salmonella enterica subsp. arizonae infection in humans. J. Clin. Microbiol. 52: 741-744.

Evangelopoulou G., G. Filioussis, S. Kritas, G. Christodoulopoulos, L.A., Triantafillou and A.R. Burriel. 2014b. Short Communication. Colonisation of pig gallbladders with Salmonella species important to public health. Vet Rec. 176 (7): 174.

European Committee for Veterinary Medicinal Products. 1994. Chloramphenicol summary report. European Agency for the Evaluation of Medicinal Products (EMEA). http://www.emea. europa.eu/ pdfs/vet/mrls/chloramphenicol.pdg, 2014.11.17.

Friendship R.M., A.Mounchili, S. McEwen and A. Rajic. 2009. Critical review of on-farm intervention strategies against Salmonella. http://development.bpex.org.uk/downloads/298614/292327/Critical\%20review\%20of\%20onfarm\%20intervention\%20strategies\%20 against\%20Salmonella.pdf, 2014.11.17.
Frye F.G. and C.R. Jackson. 2013. Genetic mechanisms of antimicrobial resistance identified in Salmonella enterica, Escherichia coli, and Enteroccocus spp. isolated from U.S. food animals. Front. Microbiol. 4: 135.

Gunn J.S. 2000. Mechanisms of bacterial resistance and response to bile. Microbes. Infect. 2: 907-913.

Healy B., S. Cooney, S. O’Brien, C. Iversen, P. Whyte, J. Nally, J.J. Callanan and S. Fanning. 2010. Cronobacter (Enterobacter sakazakii): an opportunistic foodborne pathogen. Foodborne Pathog Dis. 7: $339-350$.

Iversen C., A. Lehner, N. Mullane, E. Bidlas, I. Cleenwerck, J. Marugg, S. Fanning, R. Stephan and H. Joosten. 2007. The taxonomy of Enterobacter sakazakii: proposal of a new genus Cronobacter gen. nov. and descriptions of Cronobacter sakazakii comb. nov., Cronobacter sakazakii subsp. sakazakii, comb. nov., Cronobacter sakazakii subsp. malonaticus subsp. nov., Cronobacter turicensis sp. nov., Cronobacter muytjensii sp. nov., Cronobacter dublinensis sp. nov. and Cronobacter genomospecies . BMC Evol. Biol. 7: 64.

Janda J.M. and S.L. Abbott. 2010. The genus Aeromonas: taxonomy, pathogenicity, and infection. Clin. Microbiol. Rev. 23: 35-73.

Jensen P.O., M. Givskov, T. Bjarnsholt and C. Moser. 2010. The immune system vs. Pseudomonas aeruginosa biofilms. FEMS Immunol. Med. Microbiol. 59: 292-305.

Joseph S. and S.J. Forsythe. 2011. Predominance of Cronobacter sakazakii sequence type 4 in neonatal infections. Emerg. Infect. Dis. 17: 1713-1715.

Ljungh A., B. Wretlind and R. Mollby. 1981. Separation and characterization of enterotoxin and two haemolysins from Aeromonas hydrophila. Acta Pathogenica Microbiol. Scand. Sec. B. 89: 387-397. McWhorter A.C., R.L. Haddock, F.A. Nocon, A.G. Steigerwalt, D.J. Brenner, S. Aleksic, J. Bockemuhl and J.J. 3rd Farmer. 1991. Trabulsiella guamensis, a new genus and species of the family Enterobacteriaceae that resembles Salmonella subgroups 4 and 5. J. Clin. Microbiol. 29: 1480-1485.

Nayar R., I. Shukla and A. Sultan. 2014. Epidemiology, Prevalence and identification of Citrobacter species in clinical specimens in a tertiary care hospital in India. International Journal of Scientific and Research Publications, Volume 4, Issue 4. http://www.ijsrp.org/ research-paper-0414/ijsrp-p2843.pdf, 2014.11.17.

Pepperell C., J.V. Kus, M.A. Gardam, A., Humar and L.L. Burrows. 2002. Low-virulence Citrobacter species encode resistance to multiple antimicrobials. Antimicrob. Agents Chemother. 46: 3555-3560. Queiroga M.C., A.S.P. Amaral and S.M. Branco. 2012. Short communication. Isolation of Aeromonas hydrophila in piglets. Span. J. Agric. Res. 10: 383-387.

Quinn P.J., M.E. Carter, B. Markey and G.R. Carter. 1994. Enterobactreiaceae. In: Clinical Veterinary Microbiology, Mosby, St. Louis. Schwarz S., P. Silley, S. Simjee, N. Woodford, E. van Duijkeren, A.P. Johnson and W. Gaastra. 2010. Assessing the antimicrobial susceptibility of bacteria obtained from animals. Vet. Microbiol. 141: 1-4.

Shailesh Y., G. Manoj and S. Virender. 2012. Superbug: Reality Or Fiction. JARBS. 4: 259-261.

Sommer M.O.A. and G. Dantas. 2011. Antibiotics and the resistant microbiome. Curr. Opin. Microbiol. 14: 556-563.

Thiolas A., C. Bollet, B. La Scola, D. Raoult and J.M. Pages. 2005. Successive emergence of Enterobacter aerogenes strains resistant to imipenem and colistin in a patient. Antimicrob. Agents Chemother. 49: 1354-1358.

Wang A.J., T.E. Wang, C.C. Lin, S.C. Lin and S.C. Shih. 2003. Clinical predictors of severe gallbladder complications in acute acalculous cholecystitis. World J. Gastroenterol. 9: 2821-2823. 